\title{
READING THE WORLD WITH MATHEMATICS: A CRITICAL MATHEMATICS LITERACY CURRICULUM IN TAIWAN
}

\author{
Wen-Hua Chen \\ PhD student, Institute of Curriculum and Instruction, Department of Education, National Taiwan \\ Normal University, Taiwan \\ wenhua0923@gmail.com
}

\begin{abstract}
This study aims to go into co-constructive approaches to teaching and learning in a junior high classroom in Taiwan. It studies co-construction of curriculum from the perspectives of a mathematics teacher and the students, as the teacher and the students attempted to co-construct aspects of the Classroom Level curriculum with each other. This 3-year study focuses on exploring the practices and understandings of the co-construction process between the teacher and the students when they conduct curriculum decisionmaking at the Classroom Level. In addition, in current curriculum reform contexts in Taiwan as well as in an active globalizing world, this study also tries to understand how the teacher and the students conduct reflective practices and what they have achieved when co-constructing curriculum at the Classroom Level. This kind of interpretive study is rarely seen in Taiwan's junior high school classrooms. Multiple methods are used to collect research data, including participant observation, interviews and document analysis. Results of this study are as follows:
\end{abstract}

I. The co-construction of curriculum at the Classroom Level initiatively focused on the selection and organization of curricular experiences, including course content, learning activities, and subject matter: accuracy, precision, clarity, consistency, relevance, and good reasoning. Nevertheless, around the final year of the study, the mathematics teacher and the students gradually infused a critical thinking perspective into the co-construction of curriculum. That is, they started trying to examine those structures or elements of thought implicit in all the reasoning: purpose, question-atissue, assumptions, concepts, reasoning leading to conclusions, empirical grounding, objectiveness from alternative viewpoints, and implications and consequences.

II. The co-construction of curriculum initiatives at the Classroom Level was achieved through continuous negotiation between the mathematics teacher and the students. In order to deal with the simultaneous but incompatible opposition of opinions between the two parties, the teacher and students gradually stayed in a module as below: (1) learn a few negotiation strategies; (2) try to find out key tactics for success; (3) create a contract; (4) perform and reflect.

III. The co-construction of curriculum initiatives at Classroom Level inspired the mathematics teacher and the students to adopt a range of approaches to upgrade their reflective practice level and the tools were a starting point. The theme of the students' reflective practice often focused on mathematics problem-solving strategies and the best effective way in calculation. On the other hand, the 
mathematics teacher's reflective practice often focused on personal philosophy clarification.

IV. The co-construction of curriculum initiatives at Classroom Level facilitated the empowerment of the mathematics teacher and the students as well the quality-improvement of curriculum deliberation. Based on the long collaborative process, the teacher and the students not only used the present resources inside the classroom, but also tried to seek outside resources from School Level, Municipal Level and National Level through techniques and application of network relationship management.

Keywords: Co-construction, Critical Literacy, Reflective Practice, Network Relationship Management.

\section{INTRODUCTION}

Education makes sense because women and men learn that through learning they can make and remake themselves, because women and men are able to take responsibility for themselves as beings capable of knowing-of knowing that they know and knowing that they don't" (Freire, 2004 : 15).

The implementation of 12-year basic education system is Taiwan's goal for education. It is a milestone program for Taiwan's educational model transfer as well as the teaching and learning system transformation (MOE, 2015). Essentially, in addition to the Government Level intends to find out a way to replace either the traditional entrance exam or the highest score which allows students to enter the better ranking school, at Individual Teacher's or Teachers' Level also actively participate in and share with the duties for the achievement of concentration on learner-centered teaching and learning. Under globalization, interactionscrossing with lots of uncertain factors affect, recent years in Taiwan, there are many teachers and students begin to "flipped classroom" in their standing field. They incorporate holistic learning and skills development as well as academic learning into the 12-year basic education system, and improve themselves academic attainment monitoring mechanisms nationwide. Beside, teacher tries to enhance remedial instruction to ensure the quality of their academic attainment, to achieve excellent educational quality, and strive to achieve advanced development.

\section{RESEARCH QUESTION}

\subsection{How Was Critical Literacy Curriculum Operating In Daily Activities Classroom?}

\subsection{What Reflective Practice Did Teacher And Students Act In The Process?}

\section{LITERATURE REVIEW}

\subsection{About The Origins History Of Curriculum Negotiation Theory And Practice}

Curriculum negotiation is based upon a number of foundational ideas. John Dewey stressed the precept that quality experience must form the basis of the curriculum rather than it be external to and disconnected from children's lives; Vygotsky's idea further provided us another critical concept - Instructional scaffolding. The ZPD is a range of tasks that are within a child's cognitive ability to learn with assistance. Freire's generative themes are a student centered system of learning that challenges how knowledge is constructed in the formal education system and in society at large. Bruner (2006) laid a lot of emphasis on the importance and diversity of cultural settings. All of them provide a statement in justification of that learning is an active process connection to learners' life experiences, and the ideas which supported curriculum negotiation arose out of questions about effective learning and teaching.

\subsection{About The Contemporary Theory And Practice Related To Curriculum Negotiation: Co-Constructivist Model Of Teaching And Learning}

No sharply exact and widely accepted definition of the concept and process of the term "co-construction" can be found in psychological or educational literature. What has been provided is very diverse and depends on the theoretical context in which it is embedded. There are at least three different aspects can be found $(\mathrm{K}$. Reusser, 2001:2058): (a) the social type of discourse eligible to be called co-constructive: mother-child dialog, peer interaction, teacher-student interaction, learning in teams, computer-supported collaborative work; (b) the psych pedagogical processes involved in productive co-constructive activity: productive dialog such as exploratory talk and collective argumentation, collaborative negotiation after sociocognitive conflict or as a process of reciprocal sense-making, joint construction of a shared understanding, elaboration on mutual knowledge and ideas, giving and receiving help, tutoring and scaffolding; (c) the expected outcomes of collaboration: taken-as-shared individual vs. socially shared cognitions; convergence and intersubjectivity; academic task fulfillment, student motivation, and conceptual development; effects on skills in listening, 
discussion, disputation, and argumentation.

The co-constructivist model of teaching and learning stresses the partnership that is central to curriculum negotiation. Described as a much less familiar model than constructivist or transmission models (Agnew \& Lodge, 2000), it had a more collaborative than individual view of learning, "allowing learners to identify issues in their organization and society which affect their learning and well-being and then to act to bring about changes" (2000: 11). The role of the teacher was to initiate a dialogue between and with the students, based on their common experiences, and students were expected to be active participants. Teacher-student relationships were viewed as less "hierarchical, boundaried and fixed" (2000:12), compared with the more formal transmissible classrooms.

\subsection{Critical Literacy And Critical Mathematics Education}

There are several different theoretical perspectives on critical literacy that have produced different pedagogical approaches to teaching and learning. All of these approaches share the basic premise that literacy requires the literate consumers of text to adopt a critical and questioning approach. Freirean critical literacy is conceived as a means of empowering disempowered populations against oppression, frequently seen as enacted by corporate and/or government entities. Freirean critical literacy starts with the desire to balance social inequities and address societal problems caused by abuse of power. It proceeds from this philosophical basis to examine, analyze, and deconstruct texts. This perspective is reflected in the works of Henry Giroux, Peter McLaren, and Jean Anyon, among many others. The Freirean perspective on critical literacy is strongly represented in critical pedagogy.

This study site was in mathematics class of junior high school in Taiwan. Regarding to "Critical mathematics education", Skovsmose (2008) stated that it was an attempt to reconceive school mathematics as a site of political power, ethical contestation, and moral outrage. He limited modernity to emphasis two assumptions concerning: (1) the existence of an intimate connection between scientific and social progress; and (2) the possibility of establishing epistemic transparency. He added, modernity stretches back in time and included the period of the enlightenment that celebrated the importance of knowledge, but the extent to which modernity might stretch into the future is questionable, as notions like post-modernity, risk society, liquid modernity, hyper-complex society have gained applicability. In this study, these learners also bring with them the knowledge and experience of other cultures and languages. They can use this experience as a rich resource when exploring how languages, texts, and literacy practices are used in different contexts and how they can be seen from different perspectives. Opportunities to explore these different ways of making meaning should be incorporated into class work on the languages, texts, and literacy practices of mathematics learning area. Critical literacy involves learners and information users in:

- Rethinking and refining teacher's and students' roles in classroom.

- Questioning how knowledge is constructed and used.

- Investigating whether the writer has the authority to speak for a group or position or to tell particular stories.

- Considering how power relationships are established.

- Whether a text includes or excludes particular readers or perspectives.

- Examining the ways in which texts can position a reader.

\section{METHODOLOGY}

\subsection{Study Site}

This study site was in a junior high classroom located in New Taipei City. It's in a large-scale community high school with over 100 classes. The case teacher, this researcher, was a "Participant-as-observer" and responsible for mathematics teaching in Class AA which included 13 boys and 14 girls aged around 13year-old. Most of they were spirited and vivacious. This study period was nearly 3 years, potentially started from Aug. 2011 to Jun. 2014.

\subsection{Data Collection}

Qualitative research is the case study which examines in depth "purposive samples" to better understand a phenomenon (Yin, 1989 ; Racino, 1999). Qualitative research is designed to reveal a target audience's range of behavior and the perceptions that drive it with reference to specific topics or issues. In addition, 
multiple methods are used to collect research data including participant observation, interviews and document analysis.

\section{FINDINGS}

\subsection{The Context Of The Co-Construction Of Critical Literacy Curriculum}

\subsubsection{Teacher Deconstruct and Reconstruct her Belief}

"When I back to college for advance master course in my $2^{\text {nd }}$ teaching life, suddenly, everything became different... in master course period, I often tasted a little bitterness and felt fail in my learning..., and then, I started to understand and be willing to enter into students feelings..." (TR, 20110902)

At the initial study, the case teacher had accomplished her master course for two years. But she thought that experience impressively and had a deeply influenced on her following teaching. The teacher always reflected practices by writing, listening, reading and speaking. Clarify "teaching philosophy" is her core concern these years.

" in order to advance my learning and teaching ability, in 2012 summer, I joined Municipal Level

Counseling Group (国民教育輔㱏圆) for learning knowledge, skills, and self-question my shortage, it was very colorful life even challenge was not easy..." (TR, 20120920)

The teacher took teaching philosophy is just hers, and those beliefs may or may not belong to others. This awareness should be reflected in personal wishes. The teacher acted to change the interaction patterns in the classrooms from what students viewed as the norm of what teaching and learning should be like, so that co-construction of curriculum could be supported to begin potentially.

\subsubsection{Guide Students to Deconstruct and Reconstruct their Belief}

The case Class AA students, 13 boys and 14 girls around 13-year-old, just graduated from elementary school at the beginning of this study. Most of they were used to learn by banking and lecture style, furthermore, they always had an attitude of mind especially "wait to be spoon-fed". In addition, maybe due to see Mathematics as a subject or a tool, most students and their parents always focused on "how to get an efficiency and correct answers effectively", very few thought about the advantage and value of "problemposing" and "problem-solving" abilities. Based on that perspective, the students were separated two groups in class: one is high-achievement; the other is low-achievement.

"It (mathematics) is difficulty to me, I always can't do it well..., and I can't learn it well from elementary school and always got low score."(S15, 20120511)

"yes, I never know we could ask so many interesting and serious mathematics questions..., I always think the textbook is right and teacher is right..."(S7, 20140501)

In addition that, teacher introduced briefly the concept of "basic literacy" and "critical literacy" to class. For example, she demonstrated "how to learn mathematics on one's own" by using some useful reading comprehensive strategies (basic literacy), and commented "mathematics is a human activity that grounded in people culture" (critical literacy). As long as there are good examples in textbook or other text, teacher directly practiced and demonstrated for students.

\subsection{3. "Our 3-year-goal"}

Based on co-constructive approach, the case teacher and students scheduled and demonstrates the links between these social and political themes and the discipline of mathematics, and its critical teaching and learning, called "Our 3-year-goal", spirit based on Critical Mathematics Education. And they also developed at-least-two-lens-wear for linking Mathematics Education and critical literacy.

\section{(i) Mathematics can be interpreted as a Descriptive tool}

Mathematics is used throughout the world as an essential tool in many fields, including natural science, engineering, medicine, finance and the social sciences. Mathematicians also engage in pure mathematics, or mathematics for its own sake. Furthermore, applied mathematics, the branch of mathematics concerned with application of mathematical knowledge to other fields, inspires and makes use of new mathematical discoveries, which has led to the development of entirely new mathematical disciplines, such as statistics.

(ii) Mathematics can be as a source for decision and action 
Mathematics education can mean disempowerment or empowerment. Ole Skovsmose(2008) pointed out, it does not contain any strong 'spine', but could collapse into rigid forms and support problematic features of any social development. However, he stated, mathematics education can also contribute to the creation of a critical citizenship and support democratic ideals. The socio-political roles of mathematics are neither fixed nor determined.

\subsection{The Content Of The Co-Construction Of Critical Literacy Curriculum}

\subsubsection{Make relevant to my experiential background}

Banks (2005) explains integration of multicultural content to mean the use of examples, metaphors, and prospects from different cultural frames when examining concepts theories, paradigms, etc. In order to more closely understand the mathematics concept, the case teacher and students tried to make relevant experiences and interests to translate the familiar into the unfamiliar.

(Learning algebra)

\begin{tabular}{|c|l|}
\hline T: & $\begin{array}{l}\text { Could you have some life examples to acquire the concept "positive and negative } \\
\text { number"? }\end{array}$ \\
\hline S01: & UN...they are opposite numbers...I always calculate but seldom explain. \\
\hline S05: & $\begin{array}{l}\text { Maybe I can take some simple examples... like borrow and end money, debit and } \\
\text { credit... }\end{array}$ \\
\hline S01: & $\begin{array}{l}\text { Yes, I got it! The degree of hotness or coldness of environment! Like the weather in } \\
\text { Taiwan, temperature remains positive number, but at the South Pole, temperature } \\
\text { remains negative number. }\end{array}$ \\
\hline $\mathrm{T}:$ & Very nice. I like all your examples. Any others? \\
\hline S13: & $\begin{array}{l}\text { I read a little science books, it's very interesting. Can I supply more information about } \\
\text { South Pole? }\end{array}$ \\
\hline S13: & $\begin{array}{l}\text { In midwinter, the average temperature remains steady at around }-60^{\circ} \mathrm{C} \text {. We can't } \\
\text { image that cold situation. (class observation, 20111003) }\end{array}$ \\
\hline
\end{tabular}

The experiences and interests of students serve as one bridge. The teacher helped students represent their experience and interests with the objects numerically. In the process helping them to translate the familiar (money or temperature) into the unfamiliar (positive and negative numbers). With practice, teacher and students became increasingly skilled at developing classroom lessons and homework assignments that tapped into community and world knowledge, creating more connection between school knowledge and the students' lives.

\subsubsection{Learn content in language I can understand}

Recently, Taiwan has a rapidly multi-population with the percentage of kinds people increasing each year. According to the data of Ministry of Education Statistics (until 2015.11.11) showed, 70,229 pupils of Taiwan Indigenous Peoples family and 211,445 pupils of new ethnicity's family studied in primary and junior high schools. That attendance rate of school-age children (6 to 15 years) severally reached around $10.3 \%$ and $3.4 \%$. At Class AA, 1 boy comes from Taiwan Indigenous Peoples family, and 2 girls come from new ethnicity's family, that one girl's mother is Vietnamese, the other's is Indonesia.
"At home, In fact, we are not speaking tribal language. Chinese is the language of our heart..., we had a big family gatherings... that can be quite lively because uncles and aunts expressed greetings in tribal words that I don't understand ..."(S05, 20111019)
"Focusing on meaning that students communicate through language rather than on correcting their errors when teaching content is less threatening to students as they practice using a new language..." (TR, 20120612)

In this classroom, these boy and girls have lived for over ten years in this community and Chinese have been the main language of their heart from their born. They all are not really familiar with their tribal or mother's language. But we also found that, the pupils of new ethnicity's family have faced the same situation: they lived in a bilingual family that mothers can't speak Chinese very well. In addition to pupils of Taiwan indigenous People and new ethnicity's families, other pupils are not really in a completely the same "native 
language". Case teacher tried to learn to make academic content reasonably comprehensible to all "native speakers" in class. Parts of this involve giving students explicit instruction in plenty of opportunity to practice using their preferred language in a nonthreatening context. If a child makes a comment or answers a question using words "not clearly" or "ambiguous", teacher and other classmates would strive to incorporate into a reply a "clear" restatement of the child's utterance. The communication focus is on meaning; sometimes children will repeat or reconstruct the "clear" restatement, which helps with the learning process.

\subsubsection{Foster Collaborative Learning: Scaffolding process}

The important point is for case teacher and students to co-find-out which strategies hold their own teaching and learning attention and engage their minds and then to use those strategies, particularly when learning material that is new or difficult. Scaffolding is one of useful process for Case class AA. It refers to temporary support for learners as they learn to do something new and complex.

"Uh...Mary sat by me, she told me a good tactic in solving this exercise (see Figure 5.2.3.) She said, found out the operator symbols $\boldsymbol{X} \boldsymbol{A N D} \div$ at first, then underline the two key numbers of the former and the later of the operator symbols... I utilized her method and got correct answer, even I failed at the $2^{\text {nd }}$ exercise..." $(S 26,20111116)$

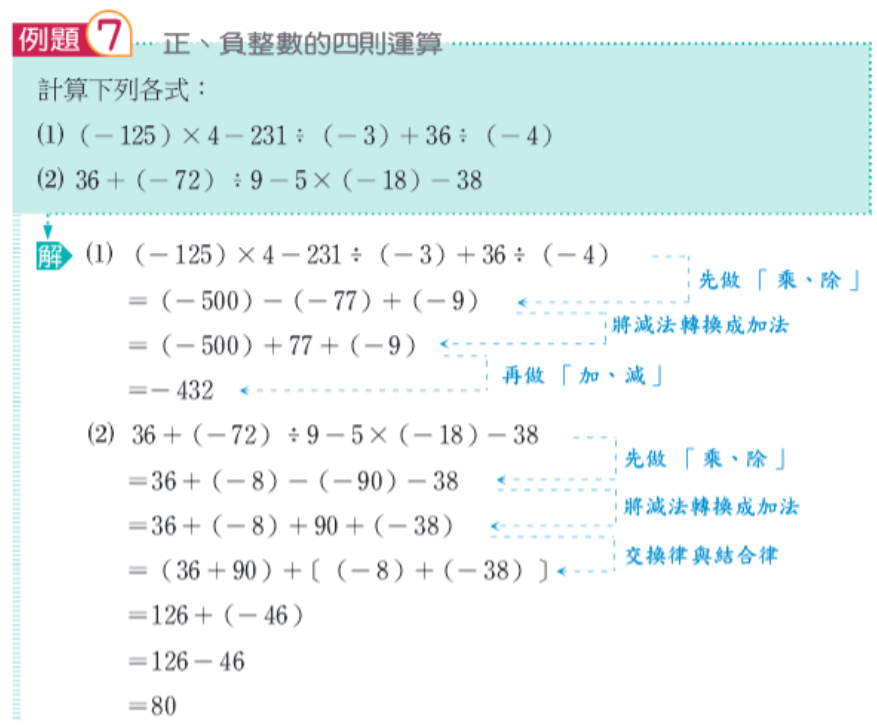

Figure 5.2.3.

\section{Resource From: NANIWEB (the first semester of 2010 academic year, p.52)}

In this case, on the other hand, we also receives a hint: although students tried to deconstruct their "old brief' and reconstruct "new brief' simultaneously at their learning beginning, they can't totally give up pursuing accuracy, precision, and efficiency. Furthermore, here is another case.

"That exercise (see Figure 5.2.3.) Is interesting but the solution is boring... after discussing with my partners, John and Aaron, we found a creative idea...here, why not firstly deal with $36+(-8)$ then we can get answer 28 , and we combined 28 with (-38) getting answer (-10), finally calculating $90+(-10)$ and get answer $80 \ldots "(\mathrm{~S} 02,20111121)$

"To combine 28 with (-38) getting answer $(-10)$, it is a cool idea..., actually I just calculated in regular succession without gaps. I am used to keep in sequential order for safety... " (S20, 20111121)

"I am a learner in the classroom. I know achievement can be enhanced when we work with each other within her or his zone of proximal development. In fact, I learned from students a lot. (TR, 20111121)"

In this case, we found that scaffolding helps learners embed different-level skills and content in differentorder thinking. It involves starting with, and accessing, what learners already know, then guiding learners in producing a new academic skill or product from there. Scaffolding process is particularly useful when learners engaging themselves in interactions that would help them to achieve more than they could achieve independently. And, based on teachers saw herself as a learner, they had more opportunities to 
communicate with each other, and co-construct their own knowledge as well as an appropriate Class $\boldsymbol{A A}$ learning style.

\subsubsection{Breaking the commonplace}

The case saw critical mathematics education as an essence with challenges emerging from the critical nature of mathematics education. They had at-least-two-lens-wear for linking Mathematics Education and critical literacy, which is "Mathematics can be interpreted as a Descriptive tool" and "Mathematics can be as a source for decision and action".

"before, after finishing the quiz, I always double-checked to gain high core...but now, I try to be aware of thinking the implication of this data showed (see Figure 5.2.4. It showed was a part of the quiz)..., how to measure the "crime number"? Where is the data from? Is the analysis correct?"(S10, 20131219)

"I was sexually harassed last month, as far as I'm concerned, how is my community crime mapping?"(S23, 20131219)
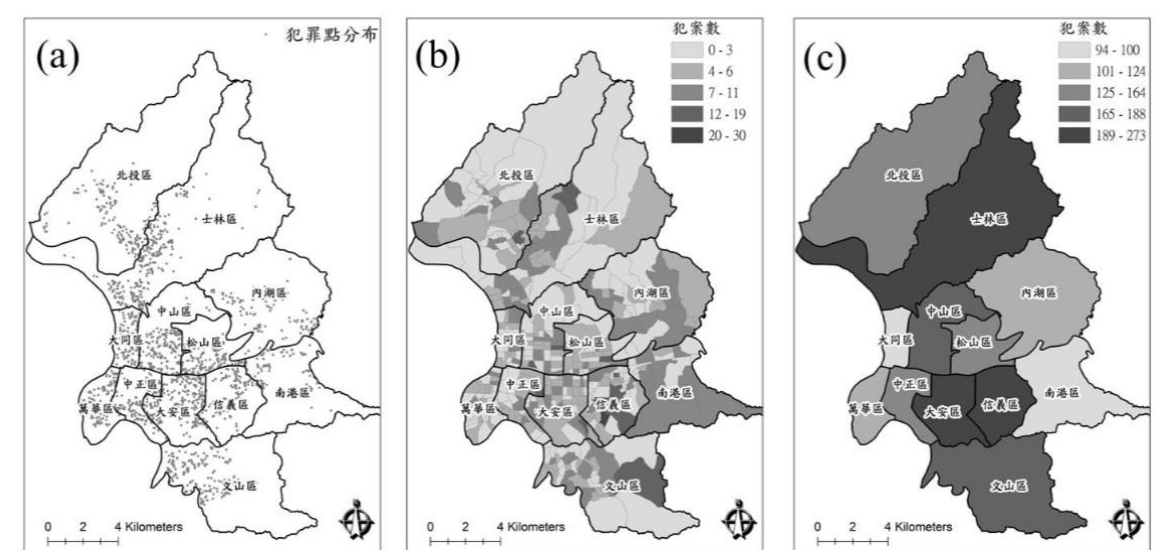

5 比較各種不同尺度加總單位的空間型態差異 : (a) 以住宅窲盜刑案個案為單位;

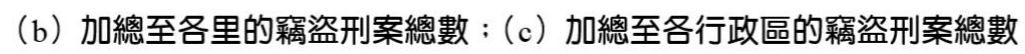

Figure 5.2.4.

Resource From: Tzai-Hung Wen Tzer-Chang Liu Min-Hau Lin (2010: 54)

In teacher and students' everyday practice, they encouraged each other to think deeply and critically examine what are they read and view. Mathematics can be interpreted not only as a descriptive tool, but also as a source for decision making and action. As the interview showed, student tried to connect the knowledge with their life experience and community environment.

\subsubsection{Considering multiple viewpoint}

\begin{tabular}{|l|l|}
\hline S18: & $\begin{array}{l}\text { Checking this data from internet, I found out the same data showed in different ways } \\
\text { within Chinese version and English version... (See Figure 5.2.5.) }\end{array}$ \\
\hline S22: & $\begin{array}{l}\text { I think that Graphs display information using visuals and tables communicate } \\
\text { information using exact numbers. They both organize data in different ways, but } \\
\text { using only one for each version is not necessarily better than using the other.” }\end{array}$ \\
\hline S18: & Ha-ha! Yes, and my English is not very good, I pass it... \\
\hline S07: & $\begin{array}{l}\text { But many foreigners in Taiwan, maybe they need these information...(class } \\
\text { observation, 20140417) }\end{array}$ \\
\hline
\end{tabular}




\begin{tabular}{|c|c|c|c|c|}
\hline 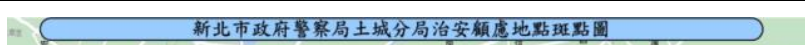 & \multicolumn{2}{|c|}{ Class of Cases } & \multirow{2}{*}{$\begin{array}{c}\text { August } \\
0 \text { case }\end{array}$} & \multirow{2}{*}{\begin{tabular}{|c|} 
Accumulated (Jan. $\sim$ Aug.) \\
8 cases \\
\end{tabular}} \\
\hline $\mathrm{m}^{\mathrm{x}}$ & \multirow{3}{*}{ Serious Crimes } & Occurrence & & \\
\hline & & Cleared & 0 case & 4 cases \\
\hline 8 & & Clearance Rate & $0.00 \%$ & $50.00 \%$ \\
\hline$\because \Delta 8$ & \multirow{3}{*}{ Common } & Occurrence & 514 cases & 4,843 cases \\
\hline 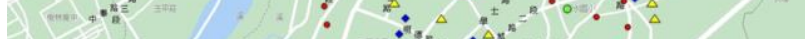 & & Cleared & 462 cases & 4,555 cases \\
\hline & & Clearance Rate & $89.88 \%$ & $94.05 \%$ \\
\hline & \multirow{3}{*}{ Automobile } & Occurrence & 36 cases & 373 cases \\
\hline & & Cleared & 45 cases & 448 cases \\
\hline & & Clearance Rate & $125.00 \%$ & $120.11 \%$ \\
\hline 国 & \multirow{3}{*}{ Motorcycle } & Occurrence & 244 cases & 1,890 cases \\
\hline$i$. & & Cleared & 235 cases & 1,972 cases \\
\hline$x=x^{n} n^{n}$ & & Clearance Rate & $96.31 \%$ & $104.34 \%$ \\
\hline 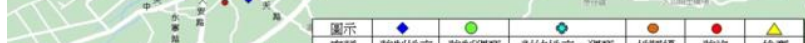 & \multirow{3}{*}{ Total } & Occurrence & 794 cases & 7,114 cases \\
\hline 20 & & Cleared & 742 cases & 6,979 cases \\
\hline & & Clearance Rate & $93.45 \%$ & $98.10 \%$ \\
\hline Chinese version(by Graph) & \multicolumn{4}{|c|}{ English version(by Table) } \\
\hline
\end{tabular}

Figure 5.2.5.

\section{Resource From: New Taipei City Police Department}

The crisis in mathematics learning among minority and low-income students is a great concern given that mathematical literacy is considered a valuable knowledge and skill in an increasingly competitive global economy and politically interdependent world. In this case, being founded on critical literacy as an openminded Len, "the notion of mathematics either right or wrong" was discarded by the teacher and students. In addition, we found culturally responsive in a mathematics classroom is to understand students' mathematical thinking, and critical mathematics curriculum involves the analysis and critique of the relationship among text, language, gender, power, social class and social practice.

\subsubsection{Taking action to promote social justice}

Curriculum exists for students. It is concerned with both content and process. Critical mathematics education challenges the neutrality of the teaching and learning of mathematics, showing how these are value-laden activities indissolubly linked to social and political life. The solutions to the real-world problem at the heart of the inquiry can be put into action - through letters to the editor, communication with state, presentation to relevant boards, or by whatever means the teacher's and students' imaginations can conjure.

This case argued that the values of openness, dialogicality, criticality towards received opinion, empowerment of the group, and social/political engagement and citizenship are necessary dimensions of the teaching and learning of mathematics. Based on both teacher and students' cooperation and collaboration, the critical mathematics education is potentially to contribute towards democracy and social justice.

\subsection{The Teacher's And Students' Reflective Practices}

\subsubsection{The Main Deliberate Component}

"The practitioner allows himself to experience surprise, puzzlement, or confusion in a situation which he finds uncertain or unique. He reflects on the phenomenon before him, and on the prior understandings which have been implicit in his behavior. He carries out an experiment which serves to generate both a new understanding of the phenomenon and a change in the situation. (Schön, 1983: 68)

In this case, teacher and students developed the co-construction of curriculum- "Our 3-year-goal", spirit based on Critical Mathematics Education. They also developed at-least-two-lens-wear for linking Mathematics Education and critical literacy. The main deliberate component parts of this curriculum were derived from the case teacher and students' reflective practices. The contents included multi-aspects (see Figure 5.3.). 


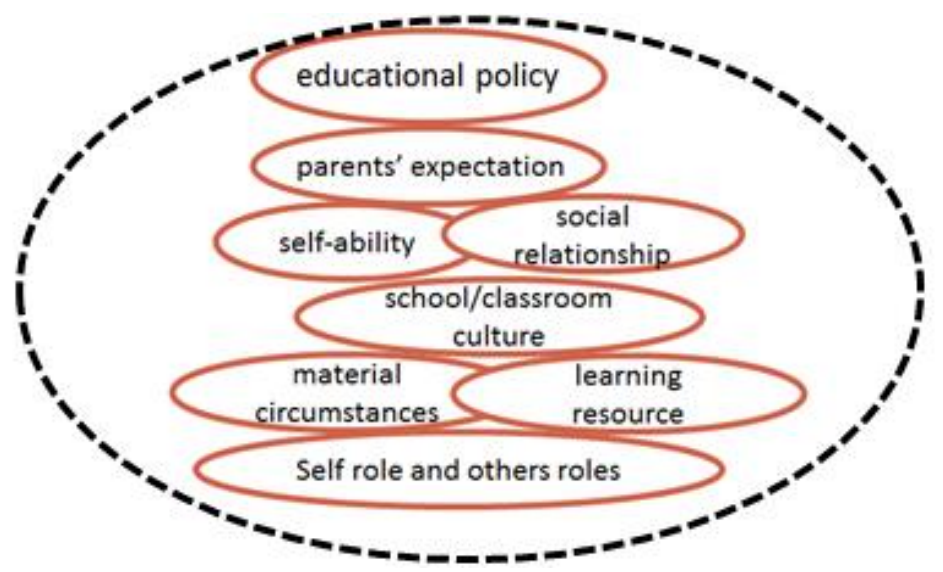

Figure 5.3.

The Main Deliberate Component of The Case's Reflective Practices.

Resource From: This Study (2015)

\subsubsection{Simultaneous but Incompatible Opposition of Opinions}

Based on the idea Knight (1985) written, this case, a closely approaching democratic classroom, will clearly establish the rights and responsibilities of both teacher and students. It requires teacher and student participation under the co-constructive guidance and as they move though the classroom, they take a broader responsibility and involvement in planning, evaluation and curriculum. Democracy is also practiced within the classroom through conflict resolution. How fair and how justice is issues resolved? Teacher and students were to hear and validate the voice of theirs in terms of curriculum then also their voice must hold value with conflict resolution. That is to say, to allow all people the opportunity to explain themselves and allow them to realize the consequence of their actions. Negotiated and democratic education function simultaneously is through allowing teaching and learning reflection or journal time pre class, during class, and after class. This was a valuable way in which teacher and students were able to articulate how they felt towards not only the co-construction of curriculum but also the culture of the classroom. This was done both verbally and in written format, or any other ways.

\subsubsection{Between Technical Rationality to Think In Action}

Donald Schön (1983) pointed out; the capacity to reflect on action so as to engage in a process of continuous learning was one of the defining characteristics of professional practice. He argued that the model of professional training which he termed "Technical rationality"- of charging students up with knowledge in training schools so that they could discharge when they entered the world of practice. Technical-rationality is a positivist epistemology of practice. It is 'the dominant paradigm which has failed to resolve the dilemma of rigor versus relevance confronting professionals'. The notions of reflection-in-action, and reflection-on-action were central to Donald Schön's efforts in this area. The former is sometimes described as 'thinking on our feet'. It involves looking to our experiences, connecting with our feelings, and attending to our theories in use. It entails building new understandings to inform our actions in the situation that is unfolding.

"Discussion with classmates is a good way for reflective practice, we always challenge and inquiry meaningful questions to each other. Social issue is gradually more and more important for class." $(\mathrm{S} 07,20140320)$

In this case, various ways or methods were used for reflective practices. For example, some kept their own diary or journal is an easy way to get started, some tried working on it with partners, doing peer review, clinical supervision or mentoring and so forth. The cultivation of the capacity to reflect in action (while doing something) and on action (after you have done it) has become an important feature of professional training programmes in many disciplines, and its encouragement is seen as a particularly important aspect of the role of the mentor of the beginning professional.

\section{CONCLUSION}

Conclusion1: The co-construction of curriculum at the Classroom Level initiatively focused on the selection and organization of curricular experiences, including course content, learning activities, and subject matter: 
accuracy, precision, clarity, consistency, relevance, and good reasoning. Nevertheless, around the final year of the study, the mathematics teacher and the students gradually infused a critical thinking perspective into the co-construction of curriculum. That is, they started trying to examine those structures or elements of thought implicit in all the reasoning: purpose, question-at-issue, assumptions, concepts, reasoning leading to conclusions, empirical grounding, objectiveness from alternative viewpoints, and implications and consequences.

Conclusion2: The co-construction of curriculum initiatives at the Classroom Level was achieved through continuous negotiation between the mathematics teacher and the students. In order to deal with the simultaneous but incompatible opposition of opinions between the two parties, the teacher and students gradually stayed in a module as below: (1) learn a few negotiation strategies; (2) try to find out key tactics for success; (3) create a contract; (4) perform and reflect.

Conclusion3: The co-construction of curriculum initiatives at Classroom Level inspired the mathematics teacher and the students to adopt a range of approaches to upgrade their reflective practice level and the tools were a starting point. The theme of the students' reflective practice often focused on mathematics problem-solving strategies and the best effective way in calculation. On the other hand, the mathematics teacher's reflective practice often focused on personal philosophy clarification.

Conclusion4: The co-construction of curriculum initiatives at Classroom Level facilitated the empowerment of the mathematics teacher and the students as well the quality-improvement of curriculum deliberation. Based on the long collaborative process, the teacher and the students not only used the present resources inside the classroom, but also tried to seek outside resources from School Level, Municipal Level and National Level through techniques and application of network relationship management.

\section{REFERENCE LIST}

Bourdieu, Pierre (1991) Language and Symbolic Power (John B. Thompson, ed.; transl. by Gino Raymond and Matthew Adamson) Cambridge: Polity Press, 37-42.

Bruner, J. S. (1986). Actual minds, possible worlds. Cambridge, MA: Harvard University Press.

Chung, S., \& Walsh, D. J. (2000). Unpacking a child-centeredness: A history of meanings. Curriculum Studies, 32(3), 215-234.

Dewey, John. 1916 (1966). Democracy and Education: An Introduction to the Philosophy of Education. New York: Free Press. pp. 259-260.

Dewey, J. (1963).Experience and education. New York: Collier Books. (Original work published 1938)

Doll, R. C. (1996). Curriculum improvement: Decision making and process (9th Ed.). Boston: Allyn and Bacon.

Freire, P. (1993). Pedagogy of the Oppressed: New Revisited 20th Anniversary Edition. New York: Continuum.

Freire, P. (2004). Pedagogy of Indignation. Boulder: Colorado, Paradigm.

Freire, P. (1990). Pedagogy of the oppressed. New York, NY: Continuum Press. (Original work published 1970.)

Foucault, Michel (1980), Power and Knowledge: Selected Interviews and Other Writings 1972-1977, edited by Colin Gordon, Harvester, London. (See in particular 'The Confession of the Flesh' [interview, 1977]).

Gee, J. (2008). Social Linguistics and Literacies: Ideology in Discourses 3rd ed. London: Routledge, Taylor and Francis Group

Hooks, B. (1994). Teaching to transgress: education as the practice of freedom. New York: Routledge.

Joseph J. Lee (2005). The native speaker: An achievable model? Asian EFL Journal, 7 (2), 152-163

Minister of Education of Republic of China (Taiwan). From http://engl Minister of Educationish.moe.gov.tw/

New Taipei City Police Department. From http://www.police.ntpc.gov.tw/cp-47-993-2.html

Paul Ernest, \& Bharath Sriraman (2015). Critical Mathematics Education Theory, Praxis and Reality. University of Montana. Lyn English.

Reusser, K. (2001). Co-constructivism in educational theory and practice. In N.J. Smelser, P. Baltes \& F.E. 
Weinert (eds.), International Encyclopedia of the Social and Behavioral Sciences. (pp. 2058-2062). Oxford: Pergamon/Elsevier Science.

Schön, D. A. (1983). The reflective practitioner: How professionals think in action. New York: Basic Books.

Schön, D. A. (1987). Educating the reflective practitioner. San Francisco: Jossey-Bass Publishers.

Skovsmose, O. (1994). Towards a philosophy of critical mathematics education. Dordrecht: Kluwer

Skovsmose, O. and Borba, M. (2004). Research Methodology and Critical Mathematics Education. In P. Valero and R. Zevenbergen (Eds.), Researching the Socio-Political.Dimensions of Mathematics Education: I ssues of Power in Theory and Methodology 207-226. Dordrecht: Kluwer.

Skovsmose, O. (2005). Travelling through education. Rotterdam: Sense Publishers.

Skovsmose, O., \& Säljö, R. (2008). Learning mathematics through inquiry. Nordic Studies in Mathematics Education, 13(3), 31-50.

The Ministry of Education Republic of China Taiwan (MOE). From http://english.moe.gov.tw/mp.asp?mp=1

Torres, C. A. (2002). Globalization, education and citizenship: solidarity versus markets? American Educational Research Journal, 39(2), 363-378.

Torres, C. A. (2014). First Freire: early writings in social justice education. New York: Teachers College Press, Teachers College Columbia University.

Tzai-Hung Wen \& Tzer-Chang Liu \&Min-Hau Lin(2010). Crime Mapping and Hotspot

Analysis: A Case Study of Residential Burglaries in Taipei City, 1998-2007 Journal of Geographical Research, 52, 43-63.

Yin, R. K. (1989), Case Study Research Design and Methods, Sage, Newbury Park.

Young, J. H. (1989). Teacher interest in curriculum committees: What factors are involved? Journal of Curriculum Studies, 21(4), 363-376. 